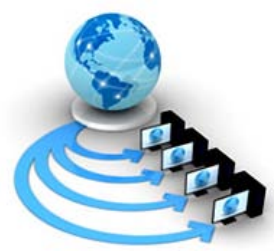

Volume 9, No. 2, March-April 2018

\title{
COMPARATIVE STUDY OF DSDV, OLSR, STAR, AODV, DSR, ZRP \& GPSR VANET ROUTING PROTOCOLS
}

\author{
Sheetal Prabha Pal \\ Department of Computer Science and Engineering \\ Lovely Professional University \\ Jalandhar, India
}

\author{
Harinder Kaur \\ Department of Computer Science and Engineering \\ Lovely Professional University \\ Jalandhar, India
}

\begin{abstract}
This Intelligent Transportation System (ITS) is a tried course to lessen the congested movement issues. ITS one of the rising use of Vehicular Ad-hoc Network (VANET). VANET is a Mobile Ad-hoc Network (MANET) in which vehicles are dynamic in nature. VANET directing conventions has been considered and examined in the previous couple of years. The point of VANET is to assemble an information framework among moving vehicles on the streets, which empowers the vehicular correspondence for wellbeing concerns. This paper includes the components of VANET along with its communication architecture. The isolated Characteristics and challenges faced by VANET is discussed. In this paper, an analysis has been made to think about directing conventions on the premise of topology based and position based on the basis of Routing information availability, Topology distribution, Path selection, Periodic route updates, Route maintenance, Routing matrix and QoS parameters.
\end{abstract}

Keywords: VANET; DSDV; OLSR; STAR; DSR; AODV; ZRP; GPSR

\section{INTRODUCTION}

In the present scenario, effective communication between nodes within the network is one of the challenges. The network used for communication is wired network or wireless network. Remote Network is of two sorts one is framework based and other is foundation less. Specially appointed system is a foundation less system. Ad-hoc network is a network consisted of number of devices communicating each other directly without having connection with access point or router. Wireless Ad-hoc network is a decentralized network. Each node participating in communication to other node and which node can transfer information dynamically is based on network connectivity. Wireless Ad-hoc devices can be of forms such as palmtop, laptop, internet mobile phones, etc. There computation power, storage space, communication capabilities and interoperability will varies tremendously. Due to dynamic topology of nodes, routing information of each node changes continuously.

One of the emerging application of vehicular ad-hoc network is ITS. In VANET, each vehicle is dynamic in nature. The communication between nodes is important aspect. The communication between the nodes is depends on various routing protocols.

\section{ARCHITECTURE AND COMMUNICATION}

This section explains the architecture of vehicular ad-hoc network. VANET comprises of various components that falls in various domains and discussion of all these domains are done under domain view. All components communicate among each other that form various communication types and that are also discussed with reference to VANET architecture.

\section{A. Components of VANET Architecture}

The design of VANET made out of keen vehicles joined with handsets and on board application, Road Side Units (RSU), brought together administration framework and correspondence connect. An essential VANET engineering contains the moving hub conveying inside the scope of other moving hub and in addition with the RSU [1]. The VANET architecture is of three possible categories: Vehicular infrastructure networks, Vehicular ad-hoc networks and hybrid Vehicular Networks [2].Vehicular infrastructure network [3] composed of fixed cellular gateways and Wireless Local Area Network (WLAN) access points. They are used as traffic intersections for routing scenarios.

According to the IEEE1471-2000 [4, 5] and ISO/IEC42010 [6] architecture standard guidelines, we are able to find that the system of VANET architecture can further be classified as follows: mobile domain, infrastructure domain and generic domain is shown in Fig 1 [7].

- Mobile space: In mobile domain, there are two domains one is vehicle domain and other is mobile device domain. The vehicle domain contains a wide range of vehicles, for example, transports and autos. The mobile device domains comprises of every single versatile gadget, for example, cell phones and individual route gadgets [8].

- Infrastructure space: In this area, there are two classes of area one is roadside framework space and focal foundation space. The roadside foundation area comprises of the RSU, for example, movement lights and focal framework space comprises of administration unit, for example, activity administration focuses (TMCs) and vehicle administration focus [8].

- Generic domain: In generic domain, there are two types of domain one is internet infrastructure domain and the other is 
private infrastructure domain. In this one or more nodes as well as servers working directly or indirectly for VANET.

The versatile space trades [9] directing data and conveys to Infrastructure area which forms information and does its own balances. At that point in second step, foundation space thusly conveys to unspecific area and trades data with it. The information among the stationary and moving assets result in productive and successfully implemented by the clients.

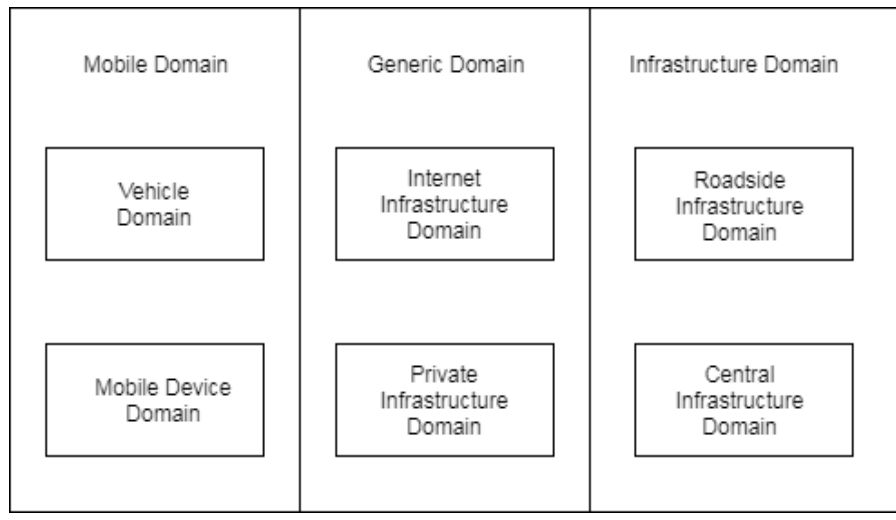

Figure 1. VANET system domains

\section{B. Communication Architecture}

The communication architecture of VANET [9] are broadly categorized on four communication types which are briefed as follows:

- Inter vehicle communication (IVC): The vehicle communication detects the inner information system and detects factors affecting the communication. Factors may be driver fatigue and drowsiness. These factors are recorded and used in concern of driver as well as public safety [1] is shown in Fig 2.

- Vehicle to Vehicle Communication (V2V): This gives information trade among vehicles in order to help drivers by advising about the basic data and cautioning messages. In V2V correspondence, it doesn't rely upon settled framework for sharing of data and it help the wellbeing and security arrangements as shown in Fig 2.

- Vehicle to road Infrastructure (V2I): In this, correspondence happens among moving vehicles and stationary RSUs for information accumulation. It permits ongoing activity and climate refreshes for drivers and gives natural detecting and checking as shown in Fig 2.

- Vehicle to broadband cloud communication (V2B): This permits the vehicular communication using wireless broadband connections such as $3 \mathrm{G}$ or $4 \mathrm{G}$. This upgrading the assistance of drivers as well as tracking of vehicles over internet that might contain more traffic information as shown in Fig 2.

\section{CHARACTERSTICS AND CHALLENGES}

VANET has its isolated characteristics from other kind of Ad-hoc networks such as MANET. These unique characteristics are discussed as follows $[3,10]$ :

A. High dynamic topology: Due to mobility of vehicles, the topology of VANET changes continuously.

B. Frequent disconnected network: Due to high mobility of node, frequent link failures occur between vehicles when they share information.

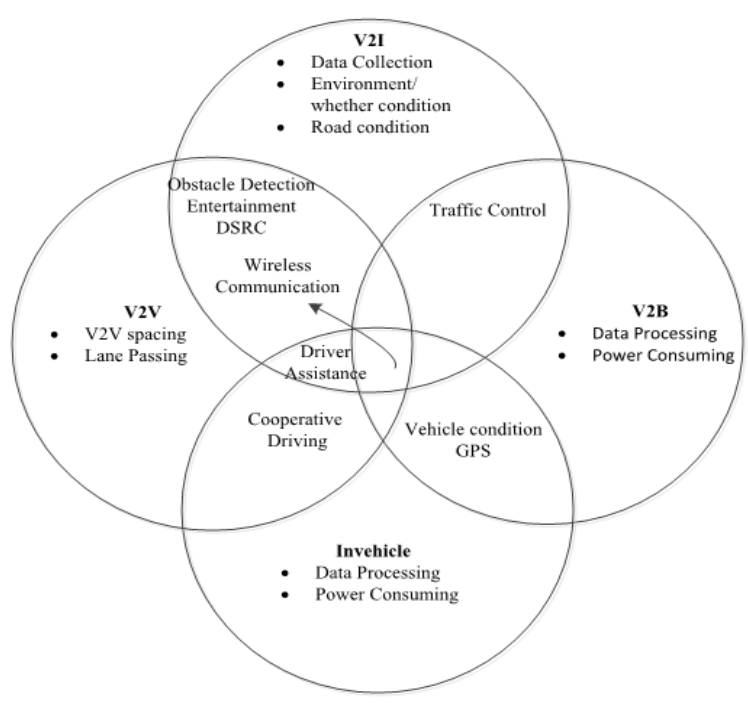

Figure 2. Functions of communication architecture [9]

C. Enough battery power and storage capacity: Intelligent vehicles carry sufficient battery power and storage capacity. So, it has sufficient storage to perform all communication and computation tasks.

D. Mobility modelling and prediction: To plan the system convention for VANET, the versatility model and expectation assumes an imperative part. In addition, vehicular hubs are typically compelled by prebuilt thruways, streets and lanes, so given the speed and the road outline, final position of the vehicle can be anticipated [10].

E. Communication environment: There are two typical communication environments one is highway scenario and other is city scenario. In highway scenario, the traffic flows in unidirectional, simple and straight forward. In city, the streets are usually separated by building, trees and other barriers.

F. Hard delay constraints: The information passing to the neighbor vehicles on time, there is no delay. The aim of this is that safety messages having high priority and are communicated within time.

G. Localization: The positions of the vehicles within the network are detected by the Global Positioning System (GPS). 
The above special aspects will generate new challenges that need to be solved in Vehicular Ad-hoc environment. The main challenges of VANET are as follows [10]:

A. Due to high mobility, the neighbor vehicles changes continuously.

B. Load on channel increasing constantly.

C. Due to distinguished received signal power, the connectivity between vehicles is irregular.

D. Loss of information due to exposed and hidden terminal problems.

\section{ROUTING PROTOCOL OVERVIEW}

The vehicles can exchange the routing information among the network to ensure the connectivity of network. To maintain the routing information of the network, we require the protocols suite. The routing protocols are classified as follows in Fig 3:

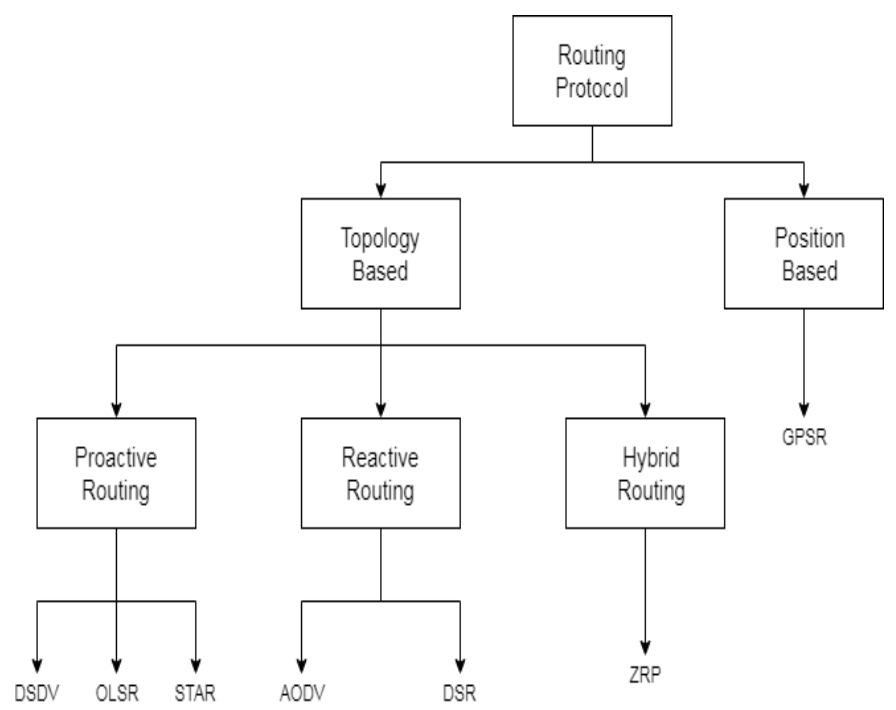

Figure 3. Routing Protocol Taxonomy

\section{A. Topology based routing protocol}

In topology based steering convention, it utilizes the worldwide data of system topology and data about the correspondence connect to settle on directing choices [11]. This protocol uses link information to forward the packets within the network. They determine the routes and preserve it in the table to do further processing [12]. The category of topology routing protocols are as follows: Reactive or on request convention, Proactive or table driven convention and Hybrid convention [13].

1) Proactive routing protocol or table driven: This category uses the shortest path algorithms such as Bellman ford's to calculate the shortest distance between two nodes [14]. It maintains the routing information and list of hops periodically and further circulate the routing information throughout the network [13]. There are some proactive protocols named as Destination Sequenced Distance Vector (DSDV), Optimized Link State Routing (OLSR) and Source Tree Adaptive Routing (STAR). a) Destination Sequenced Distance Vector (DSDV): Destination sequenced distance vector [15] uses the Distributed Bellman Fords algorithm. In this protocol, each node keeps routing table information of all the other nodes within the network and counts the hops to reach the target node is recorded. Every node have a distinguish sequence number, which is given by the target node. Sequence number distinguishes between new routes to the stale routes. To maintain consistency of network routing tables are updated periodically. To lower down the routing updates variable sized update packets are used depending on topological changes.

Each broadcast update can contain following information: Destination address, Number of Hops to reach the destination and Sequence number. There are two category of route update packets:

- $\quad$ Full dump update packet: In full dump, a node sends all the routing tables to other nodes in the network.

- Incremental update packet: A node transmits the changed entries from the last Full dump.

ARM-DSDV [16, 17], it controls to diminish the directing overhead. The refresh period control keeps up the portability grids, it depends on rate of progress of neighbors and modify it powerfully. The refresh content control keeps up the course request grid and updates it powerfully.

Randomized-DSDV [18] utilizes the irregular steering interims according to the likelihood dissemination to take out the communicate tempests of directing updates.

DSDV with different channels [19], it partitions the system layer into control and information planes. Control planes are used to send routing updates packets and data planes are used to deliver the data packets.

b) Optimized Link State Protocol (OLSR): OLSR protocol [20] enhances the link state protocol of MANET. In link state protocol all the information of routes with the neighboring nodes are broadcasted throughout the network. OLSR minimizes the size of control information: acknowledges the subset of control packets to its neighbors rather than all packets which are in the multipoint relay selectors. It reduces the broadcasting of control information by selected nodes, called multipoint relays (MPR), to broadcast the message in the network. It performs intermediate routing among the nodes in the network.

There are two categories of control messages one is hello and other is topology control [13]. Hello messages are used to check the status of link information and their neighbors. Topology message is used for diffuse the information with the next intermediate nodes, which are the part of least MPR selector lists.

c) Source Tree Adaptive Routing Protocols (STAR): STAR [21] is a proactive routing protocol. Each node determines and preserves the topology of network, builds the shortest path tree to the target node. The main idea of protocol 
is to determine the neighboring nodes and exchange the information among nodes.

This protocol uses two mechanisms to determine the neighbors:

- Hello message: Hello message is used by all the nodes periodically to update about its existence. Such messages doesn't contain any routing information, it only have small packets. When the node receive a hello packet from previously unknown node, then it update neighbors list. If a node doesn't get any message from neighbor node from a certain amount of time then updates the information of link broken or neighbor is not in the range.

- Neighbor protocol: In this no hello message is needed to support and is implemented at link layer. It declares about the new neighbors and loss of connectivity to the existing neighbors.

This protocol [22] adopts two approaches: least overhead routing approach (LORA) and optimum routing approach (ORA). It works only one approach at a time. It reduces the control overhead of packets and gives shortest routes using LORA. ORA modify the routing tables to update the information.

This protocol is effectively applicable to large scale networks to reduce the overhead and bandwidth consumption and not good enough for the highly mobile networks.

Anchor based street and traffic aware routing protocol (A-STAR) [23], in this protocol to update the routing information street map is used, for anchor path calculations to the destination node. This protocol uses an efficient recovery technique. Packets are serviced by new anchor paths. To avoid other packets to go by the used coverage area, this area is declared temporarily as "out of service". A threshold value is represented as to count times packet to retrieve the sending of stale packets.

This protocol dynamically sensed and assigned the weight to street based on the current traffic information, which provides more quality with anchor computations.

2) Reactive routing protocol or on-demand: Reactive directing convention opens the course revelation just when a hub needs to speak with the other hub [24]. It keeps up just those courses that are presently are being used, so it lessens the system overhead by taking out the support of courses [12]. Route discovery is done by flooding a query message throughout the network and this phase is complete when the connection is established [13].

The examples of on-demand routing protocols are Ad-hoc On-demand Distance Vector (AODV) [25], Dynamic State Routing (DSR).

a) Ad-hoc On-demand Distance Vector (AODV): AODV [26] is source initiated routing protocol. It is an improvement over DSDV and DSR. It minimizes the broadcast as it doesn't preserve routes from every node to other node as it only contains those routes that are currently in use. It mainly focuses on link breakage and change in network topology.
There are four message formats [25] of AODV:

- $\quad$ Route Requests (RREQs): This request is sent to the destination node via intermediate nodes to inform that source is ready for transmission.

- $\quad$ Route Replies (RREPs): As the node receive RREQs message, the target node transmits RREPs packet back to the origin node.

- $\quad$ Route Errors (RERRs): When there is any link failure in active route is detected, this message is flooded in the network to inform all the active nodes about the link failure.

- Route Reply Acknowledgement (RREP-ACK): This message is sent back to the sender to acknowledge the receipt of RREP.

\section{AODV [26] includes:}

- Path Discovery: This process is started when the source node needs to connect with the newly found node. Each node has unique sequence number and broadcast identifier. Source node starts discovery process by transmitting RREQ message to the next intermediate node. The RREQ message contain following entries such as source address, source sequence number, destination address, destination sequence number, broadcast id and hop count. Broadcast id is incremented with new RREQ issued by the source node. If the node gets multiple replicas of RREQ from next immediate nodes, it simply drops redundant RREQ and doesn't re-broadcast it.

If an intermediate node doesn't entertain the RREQ, then it keeps track through reverse path setup and forward path setup. Reverse path setup: RREQ moving from source to destination node, it automatically updates the reverse path by which all the nodes gets the RREQ request to source. In this each node conserve address of neighbor who sends first copy of RREQ. Forward path setup: Each node ahead sets the forward pointer to that hub from which it has been gotten the RREPs, invigorate the timeout data for courses.

- $\quad$ Route table management: Route is maintained at that time as it is used by any of its active neighbor. The routing entries having following entries such as: Route request expiration timer is the timer removes the entries of reverse path routing from the inactive nodes. It depends on the size of network. Route caching timeout is the time period after which the routes are declared as inactive. Active timeout period is the entry which is entertained to inform all the nodes from source to destination about the link failure.

- Path maintenance: Path among the nodes is maintained due to high mobility of nodes. When the source changes it location from previous place then the route discovery procedure will be re-initializes and find the new path. If any other or destination node changes its position, a special RREQ is sent back to source node. Hello message is sent periodically to ensure the symmetric link as well as link failures.

- Local connectivity management: The updating of local connectivity information is done when a node broadcast the message to its neighbors. It ensures that the neighbor is considered. Inactive nodes in an active path required to send "hello" messages. If message is not received from 
next hop, then the neighbor using the next hop sent the notification of link failure.

b) Dynamic Source Routing (DSR): DSR [27] receives a comparative on-request approach as AODV in regards to the course disclosure and upkeep forms. A key distinction of DSR from AODV and other on-demand conventions is the utilization of source steering, where the source hub indicates the entire grouping of middle of the road hubs for every datum parcel to achieve its goal. The source-course data is conveyed by the header of the information bundle. The favorable position of source directing is that no extra system is expected to distinguish steering circles. The conspicuous inconvenience is that information bundles must convey source courses.

The information structure DSR uses to store directing data is course reserve, with each store passage putting away one particular course from the source to a goal.

DSR makes exceptionally forceful utilization of the source directing data. Each middle of the road hub reserves the source course conveyed in an information bundle it advances, and the accompanying improvement principles to DSR have additionally been proposed:

- Rescuing: If a middle of the road hub finds that the following bounce in the source course is inaccessible, it can supplant the source course in the information parcels with a course from its own store.

- Unwarranted Route Repair: A source hub advised blunder of the bundles it begins engenders the blunder warning to its neighbors by piggy-sponsorship it on its next course ask. This helps tidy up the stores of different hubs in the system that may have the fizzled connect in one of the reserved source courses.

- Unbridled Listening: When a hub catches a bundle that is routed to another hub, it includes the source course data into its own particular course stores. The hub likewise checks if the parcel could be directed by means of itself to pick up a shorter course.

3) Hybrid routing: Half and half steering consolidates the highlights of Proactive directing convention and additionally receptive directing convention [13]. It diminishes the control overhead of proactive directing and limits the postponement of introductory course revelation of responsive steering convention [24]. Half and half directing conventions are utilized to accomplish the elite in thickly populated systems (substantial number of hubs). Key thought of Hybrid Routing Protocols is to utilize a responsive directing at the worldwide system level and to utilize a proactive in a hub's nearby neighborhood [13].The examples of hybrid routing protocol are Zone Routing Protocol (ZRP) and Zonebased Hierarchical Link State (ZHLS).

a) Zone Routing Protocol (ZRP): ZRP into a Hybrid arrangement, taking the advantages of proactive exposure inside a center point adjacent neighborhood, and using a responsive Protocol for correspondence between these zones. For the most part crossover directing conventions are zone based; it implies the number of hubs is partitioned into various zones to make course disclosure and support more dependable. Proactive steering techniques utilized as a part of this conventions among neighboring hubs working locally; in any case, responsive steering is utilized all around to search for the required hubs by questioning the required system hubs as opposed to broadcasting the question to every one of the hubs in arrange. Adaptable course disclosure and course support utilizes "Intrazone" and "Interzone" steering. Interzone directing accomplishes worldwide course revelation through receptive directing convention however intrazone controlling in see of proactive coordinating remembering the ultimate objective to keep up the course data locally within its own neighbors. The general typical for ZRP is that it decreases the framework overhead that is expedited by proactive coordinating also, it moreover handles the framework concede that is made by responsive guiding traditions and perform course disclosure more beneficially [24].

\section{B. Position based routing protocol}

As the topology of VANET changes as a rule with no earlier notice, so directing in such systems is basic assignment. Position based directing uses the position data to find the precise data of source and goal hubs and neighbor hubs [28]. The correct area of hub is controlled by utilizing GPS (Global Positioning System) or some other area administrations [13].Routing is done in bounce to jump mold to send the information bundle. The position data of every hub is found by area administrations and sending procedures which are utilized to forward the parcel to whole system [13].

The example of position based routing protocol is Greedy Perimeter Stateless Routing Protocol (GPSR).

a) Greedy Perimeter Stateless Routing Protocol (GPSR): This convention utilizes the area of the hub to specifically a sent the parcels in light of the separation. The hub nearest to the goal by sending is done on the premise by choosing the ravenous approach [13]. This procedure will proceed until the goal is come to. This convention [29] utilizes two strategies for information sending: covetous sending and edge sending. A hub sends the bundle to its neighbor hubs shut to its locale of border. In the course revelation the states are gathered and reserved in the hubs after the area of edge sending. For the investigation of portability, we utilized an arbitrary way point display [30].

\section{COMPARATIVE ANALYSIS}

Topology based and position based routing protocol has been compared on the basis of following parameters such as Routing information availability, Topology distribution, Path selection, Route maintenance, Route matrix, Route Structure, strengths and drawbacks as discussed in Table I. 
TABLE I. COMPARISION AMONG DIFFERENT PROTOCOLS

\begin{tabular}{|c|c|c|c|c|c|c|c|}
\hline \multirow{3}{*}{ Parameters } & \multicolumn{6}{|c|}{ Topology Based } & \multirow{3}{*}{$\begin{array}{c}\text { Position based } \\
\text { GPSR }\end{array}$} \\
\hline & \multicolumn{2}{|c|}{ Reactive Based } & \multicolumn{3}{|c|}{ Proactive Based } & \multirow{2}{*}{$\begin{array}{l}\text { Hybrid } \\
\text { ZRP }\end{array}$} & \\
\hline & AODV & DSR & DSDV & OLSR & STAR & & \\
\hline $\begin{array}{c}\text { Routing } \\
\text { information } \\
\text { availability }\end{array}$ & $\begin{array}{l}\text { When } \\
\text { needed }\end{array}$ & When needed & Always & Always & Always & When needed & Always \\
\hline $\begin{array}{c}\text { Topology } \\
\text { distribution }\end{array}$ & On demand & On demand & Periodical & Periodical & Periodical & $\begin{array}{c}\text { Periodical and on } \\
\text { demand }\end{array}$ & On demand \\
\hline Path Selection & Source & Source & Hop count & $\begin{array}{l}\text { Based on } \\
\text { residual energy } \\
\text { of nodes }\end{array}$ & $\begin{array}{l}\text { Using source } \\
\text { tree }\end{array}$ & $\begin{array}{c}\text { Minimum } \\
\text { battery cost } \\
\text { routing of } \\
\text { individual node }\end{array}$ & Hop count \\
\hline $\begin{array}{l}\text { Periodic route } \\
\text { updates }\end{array}$ & Not required & Not required & Required & Required & Required & Not required & Required \\
\hline $\begin{array}{c}\text { Route } \\
\text { maintenance }\end{array}$ & $\begin{array}{c}\text { Routing } \\
\text { table }\end{array}$ & Node cache & Routing table & Routing table & Routing table & $\begin{array}{c}\text { Based on local } \\
\text { connectivity }\end{array}$ & Perimeter lists \\
\hline $\begin{array}{l}\text { Routing } \\
\text { matrix }\end{array}$ & Shortest & Shortest & Shortest & Shortest & Shortest & Shortest & Shortest \\
\hline QoS support & No & No & No & Yes & Yes & Yes & Yes \\
\hline Strengths & $\begin{array}{l}\text { Used in } \\
\text { large area } \\
\text { network, } \\
\text { reduce route } \\
\text { redundancy }\end{array}$ & $\begin{array}{l}\text { No need to } \\
\text { update } \\
\text { periodically, } \\
\text { no need to } \\
\text { discover new } \\
\text { routes } \\
\end{array}$ & $\begin{array}{l}\text { No route } \\
\text { discovery is } \\
\text { required, } \\
\text { provide loop } \\
\text { free routing } \\
\text { protocol } \\
\end{array}$ & $\begin{array}{l}\text { Reduce the } \\
\text { number of } \\
\text { retransmissions } \\
\text { of packets in } \\
\text { broadcast } \\
\text { scenario }\end{array}$ & $\begin{array}{l}\text { Suitable for } \\
\text { large area } \\
\text { network, } \\
\text { reduces } \\
\text { overhead of } \\
\text { message } \\
\end{array}$ & $\begin{array}{l}\text { Combines the on } \\
\text { demand and } \\
\text { table driven to } \\
\text { make efficient } \\
\text { routing protocol }\end{array}$ & $\begin{array}{l}\text { Uses the greedy } \\
\text { technique to } \\
\text { forward } \\
\text { packets, } \\
\text { suitable for } \\
\text { highways }\end{array}$ \\
\hline Drawbacks & $\begin{array}{l}\text { Consumes } \\
\text { extra } \\
\text { bandwidth }\end{array}$ & $\begin{array}{l}\text { Packet loss is } \\
\text { high, doesn't } \\
\text { perform well } \\
\text { in high } \\
\text { mobility }\end{array}$ & $\begin{array}{c}\text { Generate a lot } \\
\text { of control } \\
\text { traffic }\end{array}$ & $\begin{array}{l}\text { Large bandwidth } \\
\text { and CPU power } \\
\text { is required to } \\
\text { compute optimal } \\
\text { path }\end{array}$ & $\begin{array}{l}\text { Large storage } \\
\text { space and } \\
\text { processing is } \\
\text { required to } \\
\text { maintain the } \\
\text { tree }\end{array}$ & $\begin{array}{l}\text { Zone size is } \\
\text { problem in this }\end{array}$ & $\begin{array}{l}\text { If GPS fails, it } \\
\text { does not able to } \\
\text { perform }\end{array}$ \\
\hline
\end{tabular}

VI.

\section{CONCLUSION}

This paper describes the communication of routing protocol for VANET. We discussed several protocol such as AODV, DSR, DSDV, OLSR, STAR, ZRP and GPSR. Route information is available in reactive and hybrid protocol when needed in comparison of proactive and position based. Topology distribution is on-demand in reactive, hybrid and position based. In proactive it is always available. Path Selection is done by source in reactive and STAR. Selection of path is done by hop count in DSDV \& GPSR and done by residual energy of node in OLSR \&ZRP. Periodic route updates is needed by only proactive based. Route maintenance is done by routing table in Proactive \& AODV. Node cache, local connectivity and perimeter lists maintains the routes in DSR, ZRP and GPSR. Routing overhead is reduced consisting of Routing information availability, Topology distribution and Periodic route updates in reactive and hybrid protocol relatively with Proactive and Position based protocol. Routing matrix is shortest for all the protocols. QoS is supported by OLSR, STAR, ZRP and

[5] M. W. Maier, D. Emery, and R. Hilliard, “ANSI/IEEE 1471 and systems engineering," Systems Engineering, vol.7, no.3, pp.257-270, 2004.

[6] D. Emery and R. Hilliard, "Every architecture description needs a framework: expressing architecture frameworks using ISO/IEC 42010," in Proceedings of the Joint Working IEEE/IFIP Conference on Software Architecture \& European Conference on Software
GPSR. Each protocol having its own strengths and drawbacks and working efficiently in different situations. For future work these protocols has been tested under highly dynamic nature or on the real map with live environment.

\section{REFERENCES}

[1] B. Ayyappan and P. M. Kumar, "Vehicular Ad Hoc Networks (VANET): Architectures, Methodologies and Design Issues”, International Conference on Science Technology Engineering and Management (ICONSTEM), pp. 177-180, 2016.

[2] M. Y. Taleb, S. Merniz and S. Harous, "Congestion Control Techniques in VANETs: A Survey”, 2017 13th International Wireless Communications and Mobile Computing Conference (IWCMC), pp. 484-488, 2017.

[3] F. li and Y. Wang, "Routing in Vehicular Ad Hoc Networks: A Survey”, IEEE Vehicular Technology Magazine, vol. 2, pp. 12-22, 2007.

[4] M. W. Maier, D. Emery, and R. Hilliard, "Software architecture: introducing IEEE standard 1471,” Computer, vol. 34, no. 4, pp. 107-109, 2001.

Architecture (WICSA/ECSA '09), pp. 31-40, Cambridge, UK, September 2009.

[7] T. Kosch, C. Schroth, M. Strassberger, and M. Bechler, Automotive Internetworking, Wiey, NewYork, NY, USA, 2012.

[8] W. Liang, Z. Li, H. Zhang, S. Wang and R. Bie, "Vehicular Ad Hoc Networks: Architectures, Research Issues, Methodologies, Challenges, and Trends”, 
International Journal of Distributed Sensor Networks, 2015.

[9] R. Tomar, M. Prateek and G. H. Sastry, "Vehicular Adhoc Network (VANET)-An Introduction”, I J C T A, pp. 8883-8888, 2016.

[10] Wang, X., “Mobile as-hoc networks”, Rijeka, Croatia: InTech, 2011.

[11] Venkatesh, A. Indra and R. Murali, "Routing Protocols for Vehicular Adhoc Networks (VANETs): A Review”, Journal of Emerging Trends in Computing and Information Sciences, vol. 5, no. 1, pp. 25-43, 2014.

[12] N. V. Pardakhe and R. R. Keole. "Analysis of Various Topology Based Routing Protocols in VANET”, International Journal of Advanced Research in Computer Science, vol. 4, no. 6, pp. 35-38, 2013.

[13] B. R. Umashankar, Nishi and R. K. Purnima, "An Overview of Position Based Routing Protocols in Mobile Ad Hoc Networks”, International Journal of Advanced Research in Computer Science \& Technology (IJARCST), vol. 2, pp. 148-151, 2014.

[14] P. Mutalik, N. S, V. J, R. V. Biradar and V. G. C. Patil, "A Comparative study on AODV, DSR and DSDV routing protocols for Intelligent Transportation System (ITS) in Metro cities for Road Traffic Safety using VANET Route Traffic Analysis (VRTA)", IEEE International Conference on Advances in Electronics, Communication and Computer Technology (ICAECCT), pp. 383-386, 2016.

[15] C.E. Perkins and P. Bhagwat, "Highly dynamic destination-sequenced distance vector routing (DSDV) for mobile computers,” in Proc. ACM SIGCOMM 94, London, UK, Oct. 1994, pp. 234-244.

[16] T. Liu and K. Liu, "Improvements on DSDV in Mobile Ad Hoc Networks”, pp. 1637-1640, 2007.

[17] S. Ahn, and A. U. Shankar, "Adapting to route-demand and mobility in ad hoc network routing," Computer Networks, Volume 38, Issue 6, April 2002, pp. 745764.

[18] A. Boukerche, and S. K. Das, "Congestion Control Performance of RDSDV Protocol in Multihop Wireless Ad Hoc Networks,” Wireless Networks, Vol. 9, Num. 3, May 2003, pp. 261-270.

[19] Fotis Diamantopoulos and A.A. Economides, “A performnance study of DSDV-based CLUSTERPOW and DSDV routing algorithms for sensor network applications," in Proc. 1st International Symposium on Wireless Pervasive Computing, Jan. 2006, pp. 1-6.

[20] P. Jacquet, P. Muhlethaler, T. Clausen, A. Laouiti, A. Qayyum and L. Viennot, "Optimized Link State Routing Protocol for*Ad Hoc Networks”, pp. 62-68, 2001.

[21] H. Jiang, "Performance Comparison of Three Routing Protocols for Ad Hoc Networks”, pp. 547-554, 2001.

[22] S. Alam and D. De, "Cloud Smoke Sensing Model for AODV,RIP and STAR Routing Protocols Using Wireless Sensor Network in Industrial Township Area”, International Conference on Research in Computational Intelligence and Communication Networks (ICRCICN), pp. 51-56, 2016.

[23] B. C. Seet, G. Liul, B. S. Leel, C. -H. Fohl, K. J. Wong, and K. K. Lee1, "A-STAR: A Mobile Ad Hoc Routing Strategy for Metropolis Vehicular Communications", International Federation for Information Processing, pp. 989-999, 2004.

[24] T. E. Ali, L. A. K. A. Dulaimi and Y. E. Majeed, "Review and Performance Comparison of VANET Protocols: AODV, DSR, OLSR, DYMO, DSDV \& ZRP”, Al-Sadeq International Conference on Multidisciplinary in IT and Communication Science and Applications (AICMITCSA), 2016.

[25] C. E. Perkins and E. M. Royer, "Adhoc OnDemand Distance Vector Routing”, Mobile Computing Systems and Applications, pp. 1-11, 1999.

[26] V. Namboodiri, M. Agarwal, and L. Gao, “A study on the feasibility of mobile gateways for vehicular ad-hoc networks," in Proceedings of the First International Workshop on Vehicular Ad Hoc Networks, pp. 66-75, 2004.

[27] D. B. Johnson and D. A. Maltz, "Dynamic Source Routing in Ad Hoc Wireless Networks," Mobile Computing, pp. 153-181, 1996.

[28] G. S. Tomar, "Position Based Routing for Wireless Mobile Ad-Hoc Networks”, IJSSST, vol. 10, no. 1, pp. 10-15.

[29] S. Benkirane, S. Mostafa, M. L. Hasnaoui and A. B. Hssane, "A New Comparative Study of Ad hoc Routing Protocol AODV and DSR in V ANET Environment Using Simulation Tools”, pp. 458-461, 2015.

[30] B. Karp, H. Kung, "GPSR: Greedy Perimeter Stateless Routing for Wireless Networks", in: Proceedings of ACM MobiCom, August 2000, pp. 243-254. 